site at Blackford Hill on the outskirts of Edinburgh, a move prompted by the continuing search of astronomers for clear skies, and the observatory on Calton Hill became the property of the city. It was used by the city as an observatory until 1937, when it was taken over by the Astronomical Society of Edinburgh. It is now run for the benefit of the public, and the Astronomical Society uses it for extra-mural classes and lectures for schools.

For the second time in the 150 years of astronomy in Edinburgh, astronomers are moving their telescopes to avoid the city lights. Only last year an observing station of the Royal Observatory of Scotland was opened at Monte Porzio, near Rome, which should benefit from the clear skies of Italy.

\section{Weather Satellites}

Communications satellites are turning out to be a boon to meteorologists, comparable with photographic satellites. There is a wide variety of plans in the offing to use satellites to collect measurements transmitted from automatic weather stations in remote regions and to relay the measurements to data collection centres. The prospect of more information from inaccessible areas, such as the oceans and polar regions, is particularly attractive. An experiment at present under way in the United States has a different emphasis, however. Its purpose is to test the feasibility of transmitting meteorological information from a meteorological centre to widely scattered stations by means of a communications satellite. Called the WEFAX, for weather facsimile experiment, its aim is the dissemination rather than the collection of information.

The object is to transmit weather data from certain meteorological centres in the United States to receiving stations in the Pacific Ocean and within the United States. The system can handle weather charts, weather forecasts and cloud cover photographs from satellites, and is in facsimile format. In the experiment, which was begun in December 1966, the transmissions are relayed by the satellite ATS I, which is in a synchronous orbit over the Pacific Ocean. Weather maps and cloud cover photographs of the Pacific area are converted into a suitable format at the National Environmental Satellite Center, Maryland, or at the World Meteorological Center, Washington, and then sent by land-line to Mojave in California.

A camera on the ATS satellite itself takes photographs of clouds over the Pacific, which are transmitted to the ground station at Mojave, where they are mailed to the National Environmental Satellite Center for transmission over the WEFAX network. The ATS camera works by focusing an image of part of the Earth through a pin-hole aperture on to a photomultiplier tube. A controlled spin of the satellite together with mechanical movement of the camera means that as the Farth is scanned across the photomultiplier tube a picture can be built up. In this way a large part of the Pacific can be scanned in about 2,000 revolutions of ATS $\mathrm{I}$, taking something like 20 minutes.

The ATS satellite, together with the WEFAX system, can also be used to forecast floods. It is proposed to collect readings from automatic river level and rainfall gauges in the United States by transmitting measurements from the gauges to the satellite. The satellite then relays the information to the Mojave ground station, which transmits the readings to Washington via the WEFAX land-line. The hydrological gauges are made to transmit readings by commands radioed from the Mojave station via ATS I. An experiment along these lines was started last August, using four automatic gauges at locations in the United States.

One of the strong points of the WEFAX system is that a large number of stations throughout the world are potentially able to receive facsimile information, largely because of the several conventional weather satellites now in service. This means that any suitably equipped station in the line of sight can receive cloud cover photographs from the satellite. The British Meteorological Office at Bracknell, for example, has for some time been recciving photographs taken by the satellite ESSA 6. All that is necessary to convert these stations to the WEFAX system is to modify them to receive the right frequency.

\section{BA at Dundee}

Thrs year the British Association for the Advancement of Science is to hold its annual meeting in Dundee. The meeting will take place from August 21 to 28, and the preliminary programme, as massive as ever, has now been published. Following the innovation of last year, the association will be holding three general symposia which are intended to appeal to scientists of all disciplines and to members of the public. The most interesting looks like being an allday meeting on disasters-their prevention, control and social effects. The demands of technology. and the benefits of large scale operation, leading to giant tankers, air-buses and nuclear power stations, have increased the scale of potential disasters. There is a need for a corresponding improvement in safety precautions. The meeting will be chaired by $\mathrm{Dr} \mathrm{H}$. M. Finniston, a deputy chairman of the British Steel Corporation, and Lord Robens, chairman of the National Coal Board, will be among the speakers. The other two symposia will be on regional planning and transport development, and factory farming.

A series of public lectures has for the first time been included in the programme; these will be illustrated and open to non-members. The programme includes Professor D. Michie on computers and the future, Dr D. E. Broadbent of the MRC Applied Psychology Research Unit at Cambridge on noise and people, and Professor R. J. Taylor of the University of Sussex on the origin of elements. But the meat of the association's programme will again be the sectional programmes. There are now fifteen sections, covering all fields of science. The engineering section includes discussions of electronics in medicine, economies of scale, and ultra-strong materials, and the general section will have a presidential address from Sir Gordon Sutherland on the brain drain.

\section{Forestry Commission Reports}

THERE have been important changes in the structure of the Forestry Commission since the seventh report from the Estimates Committee in 1963-64. The changes -described in the commission's Progress Report 1960-65, prepared for the Commonwealth Forestry 